\title{
Adiposity is a major determinant of plasma levels of the novel vasodilator hydrogen sulphide
}

\author{
M. Whiteman • K. M. Gooding • J. L. Whatmore • \\ C. I. Ball • D. Mawson • K. Skinner • J. E. Tooke • \\ A. C. Shore
}

Received: 21 November 2009 /Accepted: 12 March 2010/Published online: 23 April 2010

(C) Springer-Verlag 2010

\begin{abstract}
Aims/hypothesis Hydrogen sulphide is a recently identified endogenous endothelium-dependent vasodilator. Animal models of diabetes have shown that low plasma $\mathrm{H}_{2} \mathrm{~S}$ levels are associated with marked endothelial dysfunction and insulin resistance. However, human studies on $\mathrm{H}_{2} \mathrm{~S}$ and vascular function in health and disease are lacking.

Methods Plasma was obtained from male patients with type

2 diabetes $(n=11)$, overweight $(n=16)$ and lean $(n=11)$ volunteers. $\mathrm{H}_{2} \mathrm{~S}$ levels were determined by zinc trap spectrophotometry. Anthropometric measurements (BMI/ waist:hip ratio), lipid profile, systemic blood pressure, biochemical indices of diabetes (fasting glucose, insulin sensitivity, $\mathrm{Hb}_{1 \mathrm{Ac}}$ ) and microvascular function (minimum vascular resistance) were determined.

Results Median plasma $\mathrm{H}_{2} \mathrm{~S}$ levels (25th, 75th percentiles) in age-matched lean, overweight and type 2 diabetes individuals were $38.9(29.7,45.1) \mu \mathrm{mol} / \mathrm{l}, 22.0$ (18.6, 26.7) $\mu \mathrm{mol} / \mathrm{l}$ and $10.5(4.8,22.0) \mu \mathrm{mol} / \mathrm{l}$, respectively. Median plasma $\mathrm{H}_{2} \mathrm{~S}$ levels were significantly lower in
\end{abstract}

Electronic supplementary material The online version of this article (doi:10.1007/s00125-010-1761-5) contains supplementary material, which is available to authorised users.

M. Whiteman $(\bowtie) \cdot$ K. M. Gooding $\cdot$ J. L. Whatmore

D. Mawson · J. E. Tooke A. C. Shore

Institute of Biomedical and Clinical Science,

Peninsula Medical School, University of Exeter,

St Luke's Campus, Magdalen Road,

Exeter, Devon EX1 2LU, UK

e-mail: matt.whiteman@pms.ac.uk

K. M. Gooding · J. L. Whatmore · C. I. Ball · D. Mawson •

K. Skinner $\cdot$ J. E. Tooke $\cdot$ A. C. Shore

Peninsula National Institute of Health

Research Clinical Research Facility,

Exeter, UK patients with type 2 diabetes compared with lean $(p=0.001$, Mann-Whitney) and overweight participants $(p=0.008)$. Median plasma $\mathrm{H}_{2} \mathrm{~S}$ levels in overweight participants were significantly lower than in lean controls $(p=0.003)$. Waist circumference was an independent predictor of plasma $\mathrm{H}_{2} \mathrm{~S}$ $\left(R^{2}=0.423\right.$, standardised beta: $\left.-0.650, p<0.001\right)$. This relationship was independent of diabetes, which only contributed a further $5 \%$ to the model $\left(R^{2}=0.477\right)$. Waist circumference or other measures of adiposity (waist:hip ratio/BMI) remained independent predictors of plasma $\mathrm{H}_{2} \mathrm{~S}$ after adjustment for systolic blood pressure, microvascular function, insulin sensitivity, glycaemic control and lipid profile.

Conclusions/interpretation Plasma $\mathrm{H}_{2} \mathrm{~S}$ levels are reduced in overweight participants and patients with type 2 diabetes. Increasing adiposity is a major determinant of plasma $\mathrm{H}_{2} \mathrm{~S}$ levels.

Keywords Hydrogen sulphide · Vasodilator - Adiposity Diabetes $\cdot$ Microcirculation

$\begin{array}{ll}\text { Abbreviations } & \\ \text { CSE } & \text { Cystathionine- } \gamma \text {-lyase } \\ \text { ITT } & \text { Insulin tolerance test } \\ \text { K }_{\text {ATP }} \text { channels } & \text { ATP-dependent potassium channels } \\ \text { MVR } & \text { Minimum vascular resistance } \\ \text { STZ } & \text { Streptozotocin }\end{array}$

\section{Introduction}

Hydrogen sulphide is endogenously produced in the mammalian vasculature from the amino acids cysteine and homocysteine by the pyridoxal-5'-phosphate-dependent 
enzyme cystathionine- $\gamma$-lyase (CSE; EC 4.4.1.1) (reviewed in Whiteman and Moore [1]). Vascular $\mathrm{H}_{2} \mathrm{~S}$ acts as an endothelium- and $\mathrm{K}_{\mathrm{ATP}}$-channel-dependent vasodilator [1] and plasma and serum $\mathrm{H}_{2} \mathrm{~S}$ levels in rodents and healthy humans are reported to be in the range 40-80 $\mu \mathrm{mol} / 1$ [1]. Higher levels of $\mathrm{H}_{2} \mathrm{~S}$ have been observed in animal models of endotoxic and haemorrhagic shock, in which pharmacological inhibition of CSE using D,L-propargylgycline significantly increased blood pressure and survival (reviewed in $\mathrm{Li}$ et al. [2]). Conversely, lower $\mathrm{H}_{2} \mathrm{~S}$ levels were reported in animal models of hypertension, in which the administration of $\mathrm{H}_{2} \mathrm{~S}$ 'donors' decreased blood pressure [1]. These observations are consistent with the role of $\mathrm{H}_{2} \mathrm{~S}$ as an endogenous vasodilator.

Recently, a role for $\mathrm{H}_{2} \mathrm{~S}$ in the aetiology of diabetes has been suggested. Pancreatic synthesis of $\mathrm{H}_{2} \mathrm{~S}$ is markedly elevated in the streptozotocin (STZ) rat [3], in which biphasic effects on beta cells have been observed; at low concentrations, $\mathrm{H}_{2} \mathrm{~S}$ inhibited insulin release through $\mathrm{K}_{\mathrm{ATP}}$ dependent $/ \mathrm{Ca}^{2+}$-independent mechanisms [4], whereas higher levels induced beta cell death through endoplasmic-reticular-stress-dependent pathways [5]. However, plasma $\mathrm{H}_{2} \mathrm{~S}$ levels were lower after $\mathrm{STZ}$ treatment [3]. Similarly, in the NOD mouse, plasma levels of $\mathrm{H}_{2} \mathrm{~S}$ and the responsiveness of vascular tissue to endothelium-dependent vasodilators, such as acetylcholine, declined and aortic synthesis of $\mathrm{H}_{2} \mathrm{~S}$ were also progressively reduced as diabetic pathology increased [6].

Since there is increased risk of hypertension and cardiovascular disease and loss of vascular responsiveness to endogenous vasodilators in individuals with type 2 diabetes mellitus and obesity, we investigated whether there would also be a loss of vasodilatory $\mathrm{H}_{2} \mathrm{~S}$ in type 2 diabetes and obesity.

\section{Methods}

Participants Participants were recruited from advertisements in the local community. Individuals were excluded from the study if they had suffered a stroke or myocardial infarction, or had uncontrolled hypertension $(>160$ / $90 \mathrm{mmHg}$ ). Participants with type 2 diabetes were also excluded if they were treated with insulin. Additional exclusion criteria are listed in the Electronic Supplementary Material (ESM). Three study groups were recruited: (1) lean men $\left(\mathrm{BMI}<25.0 \mathrm{~kg} / \mathrm{m}^{2}\right) \quad(n=11)$; (2) age-matched overweight men (BMI $\left.>25.0 \mathrm{~kg} / \mathrm{m}^{2}\right)(n=16)$; and (3) agematched men with type 2 diabetes who were BMI matched (to within $\pm 2 \mathrm{~kg} / \mathrm{m}^{2}$ ) to the overweight non-diabetic men $(n=11)$. Participants' characteristics are shown in Table 1. All assessments were performed in a temperature-controlled laboratory $\left(22.0 \pm 0.5^{\circ} \mathrm{C}\right)$ with the participants having fasted from 22:00 hours the previous evening and having taken no medication on the morning (09:00 hours) of the tests. All patients provided written informed consent. The study was approved by the Devon and Torbay Ethics Committee and was performed in accordance with principles of the Declaration of Helsinki.

Measurement of plasma $\mathrm{H}_{2} \mathrm{~S}$ Peripheral blood samples (10 ml; EDTA anti-coagulated) were collected as described previously $[1,3,4,6] . \mathrm{H}_{2} \mathrm{~S}$ levels were determined in triplicate as described previously [1-6] and concentrations calculated against a calibration curve of sodium sulphide (1.06-100 $\mu \mathrm{mol} / \mathrm{l}$; Sigma-Aldrich, MO, USA). Briefly, $250 \mu \mathrm{l}$ zinc acetate $(1 \% \mathrm{wt} / \mathrm{vol}$. in water) was injected into $200 \mu \mathrm{l}$ plasma in tightly sealed Eppendorf vials followed by injection of $133 \mu \mathrm{l} N, N$-dimethyl- $p$-phenylenediamine sulphate $(20 \mathrm{mmol} / \mathrm{l}$ in $7.2 \mathrm{~mol} / \mathrm{l} \mathrm{HCl}$; Sigma-Aldrich $)$ and $133 \mu \mathrm{FeCl}_{3}(30 \mathrm{mmol} / 1$ in $1.2 \mathrm{~mol} / \mathrm{l} \mathrm{HCl}$; Sigma-Aldrich) $[1,3,4,6]$. After incubation in the dark for 30 min, samples were centrifuged at 5,000 $\mathrm{g}$ for $10 \mathrm{~min}$ and the absorbance of the supernatant fraction at $670 \mathrm{~nm}$ determined. The intraassay coefficient of variation was $0.1-3.76 \%$ over the concentration range studied $(n=12)$. No significant interference was observed in the presence of physiological concentrations of sulphite $\left(\mathrm{SO}_{3}{ }^{2-}\right)$, sulphate $\left(\mathrm{SO}_{4}{ }^{2-}\right)$, thiosulphate $\left(\mathrm{S}_{2} \mathrm{O}_{3}{ }^{2-}\right)$, reduced glutathione, oxidised glutathione, cysteine, cystine, homocysteine, homocystine, cystathionine, methionine, nitrite $\left(\mathrm{NO}_{2}{ }^{-}\right)$or nitrate $\left(\mathrm{NO}_{3}{ }^{-}\right)$, ( $p=\mathrm{NS}$, Kruskal-Wallis; $n=4$ ). At physiological $\mathrm{pH}, \mathrm{H}_{2} \mathrm{~S}$ $\left(\mathrm{p} K_{\mathrm{a}} 7.04\right)$ dissociates to the hydrosulphide anion $\left(\mathrm{HS}^{-}\right)$and the sulphide anion $\left(\mathrm{S}^{2-}\right)$ [1]. Therefore, we use the term $\mathrm{H}_{2} \mathrm{~S}$ to refer to the sum of these species $\left(\mathrm{H}_{2} \mathrm{~S}, \mathrm{HS}^{-}\right.$and $\left.\mathrm{S}^{2-}\right)$ present at physiological $\mathrm{pH}[1,3,4]$.

Systemic blood pressure Supine blood pressure was measured from the left arm using a semi-automatic blood pressure recorder (Critikon Dinamap, Deltona, FL, USA). Five measurements were obtained at 1 min intervals and the mean of the final three readings was taken to be the representative blood pressure.

Microvascular assessment Maximum hyperaemia was assessed by heating a small area of skin to $42-44^{\circ} \mathrm{C}$ [7], which induces maximum hyperaemia. This was achieved by attaching a small brass heater (area $0.76 \mathrm{~cm}^{2}$ ) to the dorsum of the foot for $30 \mathrm{~min}$. The resultant maximum hyperaemic response was assessed by single-point laser Doppler fluximetry (LDF; Perflux Pf2: Perimed, Järfälla Sweden), eight equally spaced measurements were made within the heated area and the mean used to represent maximum hyperaemia, arbitrarily expressed as volts. Dayto-day intra-individual variation with this technique is $6.6 \%$ (mean \pm standard deviation: $1.81 \pm 0.12 \mathrm{~V}$ ) in one partici- 
Table 1 Participant demographics
Data are expressed as number of individuals $(n)$, years, percentage (\%) or as quantitative SI units with mean $\pm \mathrm{SD}$ ${ }^{*} p \leq 0.05,{ }^{* * *} p \leq 0.001$ for lean compared with overweight participants

${ }^{\dagger} p \leq 0.05,{ }^{\dagger \dagger} p \leq 0.01,{ }^{\dagger \dagger} p \leq 0.001$ for overweight compared with type 2 diabetic participants ${ }^{\star} p \leq 0.05, * p \leq 0.01, * * p \leq 0.001$ for type 2 diabetic compared with lean participants bpm, beats per min

\begin{tabular}{|c|c|c|c|}
\hline \multirow[t]{2}{*}{ Variable } & \multicolumn{3}{|l|}{ Group } \\
\hline & Lean & Overweight & Type 2 diabetes \\
\hline \multicolumn{4}{|l|}{ Physical characteristics } \\
\hline$n$ & 11 & 16 & 11 \\
\hline Age (years) & $54.8 \pm 16.46^{\mathrm{NS}}$ & $65.00 \pm 6.06^{\mathrm{NS}}$ & $61.0 \pm 8.38^{\mathrm{NS}}$ \\
\hline Race $(n)$ & White (11) & White (16) & White (11) \\
\hline Duration of diabetes (years) & - & - & $9.00 \pm 4.4$ \\
\hline BMI & $23.31 \pm 1.3^{* * *}$ & $28.0 \pm 1.3^{\mathrm{NS}}$ & $30.0 \pm 2.4$ 林 \\
\hline Waist circumference $(\mathrm{cm})$ & $86.1 \pm 6.6^{* * *}$ & $99.8 \pm 2.8^{\mathrm{NS}}$ & $102.3 \pm 2.8^{\text {tat }}$ \\
\hline Hip circumference $(\mathrm{cm})$ & $100.3 \pm 3.3^{* * *}$ & $104.9 \pm 2.3^{\mathrm{NS}}$ & $104.6 \pm 4.9^{\ddagger}$ \\
\hline Waist:hip ratio & $0.86 \pm 0.05^{* * *}$ & $0.95 \pm 0.03^{\dagger}$ & $0.98 \pm 0.02^{\text {tat }}$ \\
\hline \multicolumn{4}{|l|}{ Macrovascular characteristics } \\
\hline Systolic blood pressure (mmHg) & $117.7 \pm 8.4^{* * *}$ & $136.0 \pm 8.9^{\mathrm{NS}}$ & $143.8 \pm 10.7^{+1 t}$ \\
\hline Diastolic blood pressure (mmHg) & $69.7 \pm 7.3^{* * *}$ & $83.2 \pm 7.9^{\mathrm{NS}}$ & $83.6 \pm 6.2^{\text {t木 }}$ \\
\hline Heart rate $(\mathrm{bpm})$ & $70.4 \pm 6.7^{\mathrm{NS}}$ & $69.12 \pm 7.0^{\mathrm{NS}}$ & $70.4 \pm 12.5^{\mathrm{NS}}$ \\
\hline \multicolumn{4}{|l|}{ Microvascular characteristics } \\
\hline Maximum hyperaemia (V) & $2.1 \pm 0.7^{\mathrm{NS}}$ & $1.9 \pm 0.5^{\dagger \dagger}$ & $1.3 \pm 0.3^{+t}$ \\
\hline Minimum vascular resistance $(\mathrm{mmHg} / \mathrm{V})$ & $47.1 \pm 21.7^{\mathrm{NS}}$ & $53.8 \pm 14.4^{\dagger \dagger \dagger}$ & $84.0 \pm 20.5$ tt \\
\hline \multicolumn{4}{|l|}{ Biochemical characteristics } \\
\hline Fasting glucose (mmol/1) & $4.8 \pm 0.4^{*}$ & $5.3 \pm 0.7^{\dagger}$ & $7.7 \pm 3.7^{+1+}$ \\
\hline $\mathrm{Hb}_{1 \mathrm{Ac}}(\%)$ & $5.3 \pm 0.3^{*}$ & $5.8 \pm 0.5^{\dagger \dagger \dagger}$ & $8.0 \pm 1.2^{\text {tt }}$ \\
\hline Total cholesterol (mmol/1) & $5.1 \pm 1.0^{\mathrm{NS}}$ & $5.5 \pm 0.8^{\dagger \dagger}$ & $4.3 \pm 1.2^{\mathrm{NS}}$ \\
\hline HDL (mmol/l) & $1.5 \pm 0.3^{\mathrm{NS}}$ & $1.4 \pm 0.3^{\mathrm{NS}}$ & $1.1 \pm 0.4^{\mathrm{NS}}$ \\
\hline Cholesterol:HDL ratio & $3.6 \pm 0.8^{\mathrm{NS}}$ & $3.8 \pm 0.7^{\mathrm{NS}}$ & $4.2 \pm 1.9^{\mathrm{NS}}$ \\
\hline $\mathrm{LDL}(\mathrm{mmol} / \mathrm{l})$ & $3.2 \pm 0.9^{\mathrm{NS}}$ & $3.2 \pm 0.9^{\dagger}$ & $2.2 \pm 0.9^{*}$ \\
\hline Triacylglycerol (mmol/l) & $1.1 \pm 0.3^{\mathrm{NS}}$ & $1.2 \pm 0.4^{\mathrm{NS}}$ & $3.2 \pm 4.2^{\mathrm{NS}}$ \\
\hline Insulin sensitivity ITT (pmol $1^{-1} \min ^{-1}$ ) & $-0.2 \pm 0.1^{\mathrm{NS}}$ & $-0.2 \pm 0.1^{\dagger \dagger}$ & $-0.1 \pm 0.1^{\text {t* }}$ \\
\hline Insulin sensitivity (HOMA \%S) & $185.3 \pm 59.6^{* * *}$ & $102.6 \pm 38.5^{\dagger \dagger \dagger}$ & $42.4 \pm 12.6^{\text {t+ }}$ \\
\hline \multicolumn{4}{|l|}{ Medication } \\
\hline Sulfonylureas $(n)$ & - & - & 9 \\
\hline Anti-hypertensives $(n)$ & - & 1 & 6 \\
\hline Diuretics $(n)$ & - & 2 & 6 \\
\hline Lipid-lowering $(n)$ & - & 2 & 5 \\
\hline Other characteristics & - & & \\
\hline Background retinopathy $(n)$ & - & - & 1 \\
\hline Microalbuminuria $(n)$ & - & - & 3 \\
\hline
\end{tabular}

pant assessed over five separate occasions. Minimum vascular resistance (MVR) of the skin microcirculation was calculated by dividing mean arterial pressure (MAP) by maximum hyperaemia $(\mathrm{MVR}=\mathrm{MAP} / \mathrm{MH}, \mathrm{mmHg} / \mathrm{V})$ [7].

Insulin sensitivity assessments Central insulin sensitivity was calculated by HOMA insulin sensitivity, based on fasting insulin and glucose levels [8]. Peripheral insulin sensitivity was assessed using a $15 \mathrm{~min}$ continuous insulin tolerance test (ITT) [7]. A bolus of $0.1 \mathrm{U} \mathrm{kg}^{-1}$ of insulin (Human Actrapid; Novo Nordisk Pharmaceuticals, Crawley, UK) was administered into a vein at the site of the anticubital fossa.
Blood samples for the determination of blood glucose were taken each minute until the blood glucose level reached $3 \mathrm{mmol} / \mathrm{l}$ or $15 \mathrm{~min}$ duration was reached [7]. The glucose samples were measured in duplicate (YSI2300 Stat Plus; Yellowsprings Instruments, Yellowsprings, OH, USA). The slope of the blood glucose curve was used to represent insulin sensitivity [7].

Biochemical variables All blood samples were obtained after assessment of microcirculatory function. $\mathrm{Hb}_{\mathrm{A} 1 \mathrm{c}}$ (normal range $4.0-6.0 \%$ ) was determined using an in-house high performance liquid chromatography method (Hewlett Packard 1050 HPLC) [7]. Fasting glucose was determined 
using a glucose oxidase method (GOD-PAP; Roche Modular analyser, Roche Diagnostics, Lewes, UK) [7]. Triacylglycerol, lipids and cholesterol were determined using a colorimetric assay (using a Vitros Analyser; Johnson \& Johnson Clinical Diagnosis, Amersham, UK) [7]. An electrochemiluminescence assay was used for the determination of fasting plasma insulin $(0.05 \%$ cross-reactivity with human proinsulin) (Cobas; Roche, Basel, Switzerland) [7].

Statistical analysis Statistical analysis was performed by the Statistical Package for Social Sciences (SPSS) version 15.0 (Chicago, IL, USA). The Mann-Whitney test was used for between-group analyses. To enable the examination of associations between $\mathrm{H}_{2} \mathrm{~S}$ levels and diabetes and obesity, data from the three participant groups were merged $(n=38)$ to generate a continuum of data. An adiposity measure (waist circumference, waist:hip ratio or BMI) and diabetes status were initially entered into a forced regression model. To determine whether the relationship between plasma $\mathrm{H}_{2} \mathrm{~S}$ with obesity and diabetes status was influenced by their related milieu, potential confounders-such as systolic blood pressure, fasting glucose, $\mathrm{Hb}_{\mathrm{Alc}}$, minimum vascular resistance, insulin sensitivity as assessed by both HOMA and insulin tolerance test-were each entered into separate regression models. Data were checked to ensure the assumptions required for regression analysis were fulfilled. This study was powered to detect a betweenindividual difference of 1.4 standard deviations, and a large effect size $\left(f^{2}=0.420\right)$ with three predictors in the linear regression model at the 5\% level with $90 \%$ power. $p$ values less than 0.05 were considered significant.

\section{Results}

Participant demographics are shown in Table 1. Median plasma $\mathrm{H}_{2} \mathrm{~S}$ levels (25th, 75th percentiles) in lean controls, overweight volunteers and men with type 2 diabetes were $38.9(29.7,45.1) \mu \mathrm{mol} / 1,22.0(18.6,26.7) \mu \mathrm{mol} / 1$ and 10.5 $(4.8,22.0) \mu \mathrm{mol} / 1$, respectively (Fig. 1). Median plasma $\mathrm{H}_{2} \mathrm{~S}$ levels were significantly lower in patients with type 2 diabetes compared with age-matched controls $(p=0.001)$ and overweight men $(p=0.008)$, presumably because of the increased adiposity of the type 2 diabetes group. Median plasma $\mathrm{H}_{2} \mathrm{~S}$ levels in overweight volunteers were also significantly lower than in lean age-matched controls ( $p=$ $0.003)$. In the univariate analysis, plasma $\mathrm{H}_{2} \mathrm{~S}$ was negatively correlated with systolic $(r=-0.580, p<0.001)$ and diastolic $(r=-0.527, p<0.001)$ blood pressures, glycaemic control (fasting glucose, $r=-0.494, p=0.001$; $\mathrm{Hb}_{1 \mathrm{Ac}}, r=-0.423, p=0.006$ ) and insulin sensitivity (peripheral insulin [ITT], $r=-0.497, p=0.004$; central insulin [HOMA],

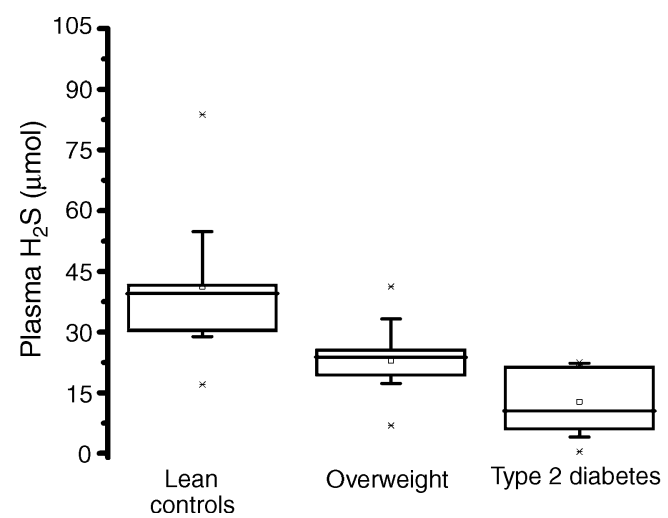

Fig. 1 Plasma $\mathrm{H}_{2} \mathrm{~S}$ levels in lean healthy and overweight volunteers and patients with type 2 diabetes mellitus. Plasma (EDTA) was collected from participants and each sample analysed in triplicate for $\mathrm{H}_{2} \mathrm{~S}$ as described in the Methods. Data are expressed as median (25th and 75th percentiles). All samples were age matched. Overweight volunteers were matched by BMI to type 2 diabetic patients. The Mann-Whitney test was used to determine differences between sample groups with significance set at $p<0.05$. Lean controls vs overweight ( $p=0.003)$, lean controls vs type 2 diabetic patients ( $p=$ $0.001)$, overweight vs type 2 diabetic patients $(p=0.008)$. Outlying data points are shown by crosses

$r=0.566, p<0.001)$. Microvascular function tests further showed significant associations with plasma $\mathrm{H}_{2} \mathrm{~S}$ (maximum hyperaemia, $r=0.402, p=0.008$; minimum vascular resistance, $r=-0.436, p=0.004)$. However, the strongest correlations were observed with measurements of adiposity i.e. waist circumference $(r=-0.650, p<0.001)$, waist:hip ratio $(r=-0.657, p<0.001)$, BMI $(r=-0.609, p<0.001)$ and, to a lesser extent, hip circumference $(r=-0.358, p=0.017)$. Regression analysis suggested that adiposity, as assessed by waist circumference, but not diabetes status was a significant independent predictor of plasma $\mathrm{H}_{2} \mathrm{~S}$ levels (waist circumference: standardised beta: $-0.543, p=0.001$; diabetes status: standardised beta: $-0.257, p=0.077$ ). The observed independent relationship between waist circumference and plasma $\mathrm{H}_{2} \mathrm{~S}$ remained after adjusting for the potential confounders: systolic blood pressure, minimum vascular resistance, age, central insulin sensitivity (HOMA) and total cholesterol:HDL ratio (standardised beta range of -0.432 to $-0.541, p$ value range $0.01-0.001$; ESM Table 1). Similar trends were observed between plasma $\mathrm{H}_{2} \mathrm{~S}$ and other measures of adiposity (i.e. waist:hip ratio and BMI; ESM Tables 2 and 3, respectively). Waist: hip ratio, but not BMI or waist circumference, was an independent predictor of plasma $\mathrm{H}_{2} \mathrm{~S}$ levels when adjusting for peripheral insulin sensitivity (waist:hip ratio: $-0.407, p=$ 0.029 ; waist circumference: $-0.283, p=0.109$; BMI: -0.183 , $p=0.329)$, suggesting that the relationship between adiposity and plasma $\mathrm{H}_{2} \mathrm{~S}$ may be related to peripheral insulin sensitivity. However, diabetes status was not a significant independent predictor of plasma $\mathrm{H}_{2} \mathrm{~S}$ in any of these models in this study. 


\section{Discussion}

It is well established that diabetes is associated with the clustering of central obesity, dyslipidaemia, raised blood pressure, hyperglycaemia and increased risk of cardiovascular disease [9]. However, the precise molecular mechanisms underpinning these clinical associations are currently not known. $\mathrm{H}_{2} \mathrm{~S}$ is emerging as important vasodilatory intermediate, inducing endothelium-dependent and $\mathrm{K}_{\mathrm{ATP}}$ channel-dependent vasorelaxation in vitro and in vivo. Our current observations that plasma $\mathrm{H}_{2} \mathrm{~S}$ levels negatively correlated with systolic and diastolic blood pressure, microvascular dysfunction, glycaemic control and insulin sensitivity are the first in man and are consistent with the observations in animal models of diabetes and hypertension $[1,3,6]$.

A potential role for CSE-derived $\mathrm{H}_{2} \mathrm{~S}$ in adipose fat metabolism has also been proposed in rats [10]. In our study, the major determinant of plasma $\mathrm{H}_{2} \mathrm{~S}$ levels was adiposity. This relationship was not accounted for by diabetes status, glycaemic control, blood pressure, microvascular function, lipids or central insulin sensitivity. However, when adjusting for peripheral insulin sensitivity, the independent relationships of plasma $\mathrm{H}_{2} \mathrm{~S}$ levels with BMI and waist circumference-but not waist:hip ratiowere lost, suggesting that peripheral insulin sensitivity may be contributing to the relationship between adiposity and plasma $\mathrm{H}_{2} \mathrm{~S}$.

A limitation of the current study is the potential for a type 2 error. However, the fact that $\mathrm{H}_{2} \mathrm{~S}$ was consistently associated with adiposity as assessed by BMI, waist circumference and waist:hip ratio, endorses the proposal that an increase in adiposity is associated with a reduction in plasma levels of $\mathrm{H}_{2} \mathrm{~S}$. However, further longitudinal studies with increased sample sizes are required to substantiate the precise relationship between plasma levels of $\mathrm{H}_{2} \mathrm{~S}$ and diabetes.

In summary, our study has shown that adiposity is a major determinant of plasma levels of $\mathrm{H}_{2} \mathrm{~S}$. The loss of the vasodilatory gas $\mathrm{H}_{2} \mathrm{~S}$ could represent a novel mechanism for mediating cardiovascular complications in obesity and type 2 diabetes. Whether this loss occurs because of reduced $\mathrm{H}_{2} \mathrm{~S}$ synthesis, enhanced enzymatic removal or increased consumption by oxidants known to be elevated in the diabetic milieu requires further attention.

Acknowledgements This work was supported by the Peninsula National Institute for Health Research (NIHR) Clinical Research Facility and funded by the Northcott Devon Medical Research Foundation, the Diabetes Research and Education Centre Trust (DIRECT) and Diabetes UK. The opinions expressed by the authors of this manuscript are not necessarily those of NIHR, the National Health Service or the Department of Health (England and Wales).

Duality of interest The authors declare that there is no duality of interest associated with this manuscript.

\section{References}

1. Whiteman M, Moore PK (2009) Hydrogen sulfide and the vasculature: a novel vasculoprotective entity and regulator of nitric oxide bioavailability? J Cell Mol Med 13:488-507

2. Li L, Hsu A, Moore PK (2009) Actions and interactions of nitric oxide, carbon monoxide and hydrogen sulphide in the cardiovascular system and in inflammation - a tale of three gases! Pharmacol Ther 123:386-400

3. Yusuf M, Huat BTK, Hsu A, Whiteman M, Bhatia M, Moore PK (2005) Streptozotocin-induced diabetes in the rat is associated with enhanced tissue hydrogen sulfide biosynthesis. Biochem Biophys Res Commun 333:1146-1152

4. Ali MY, Whiteman M, Low CM, Moore PK (2007) Hydrogen sulphide reduces insulin secretion from HIT-T15 cells by a KATP channel-dependent pathway. J Endocrinol 195:105-112

5. Yang $\mathrm{G}$, Yang $\mathrm{W}, \mathrm{Wu} \mathrm{L}$, Wang $\mathrm{R}$ (2007) $\mathrm{H}_{2} \mathrm{~S}$, endoplasmic reticulum stress, and apoptosis of insulin-secreting beta cells. J Biol Chem 292:16567-16576

6. Brancoleone V, Roviezzo F, Velleco V, De Gruttola L, Bucci M, Cirino $\mathrm{G}$ (2008) Biosynthesis of $\mathrm{H}_{2} \mathrm{~S}$ is impaired in non-obese diabetic (NOD) mice. Br J Pharmacol 155:673-680

7. Middlebrooke AR, Elston LM, Macleod KM et al (2006) Six months of aerobic exercise does not improve microvascular function in type 2 diabetes mellitus. Diabetologia 49:22632271

8. Matthew DR, Hosker JP, Rudenski AS, Naylor BA, Treacher DF, Turner RC (1985) Homeostasis model assessment: insulin resistance and beta cell function from fasting glucose and insulin concentrations in man. Diabetologia 28:214-419

9. Hajer GR, van Haeften TW, Visseren FL (2008) Adipose tissue dysfunction in obesity, diabetes, and vascular diseases. Eur Heart J 29:2959-2971

10. Feng X, Chen Y, Zhao J, Tang C, Jiang Z, Geng B (2009) Hydrogen sulfide from adipose tissue is a novel insulin resistance regulator. Biochem Biophys Res Commun 380:153-159 